\title{
New risks ahead for the Historical Peninsula, the mystic gateway of Istanbul to the World
}

\author{
S. Turgut \\ Department of Urban \& Regional Planning, Ylldız Technical University, \\ Turkey
}

\begin{abstract}
The Historical Peninsula, one of the most unique and ancient urban settlement areas of İstanbul, has also been named as a cultural heritage of UNESCO, and is a very unique and characteristic area. It has also been a symbol of İstanbul's two different municipal districts, i.e., the Fatih and Eminönü Municipalities, governing the peninsula. The Eminönü area, which is located in this region being almost a cornerstone of İstanbul's identity, stood out and was practically a symbol of the city in each of the civilizations that İstanbul witnessed during its thousands of years of history with the unique mission that the city has assumed. In addition, the area has maintained its function up until today as the collection and distribution center of goods and services in the context of commercial relationships and economic activities. The Fatih region has embraced its extremely diverse cultural mosaics and residential image, with neighbors living side by side and having mutual support with Eminönü for many centuries. These two very important districts, which are very important for the city with respect to urban memory and localities, have faced a different implementation in recent times. As a result of a series of administrative border revision decisions made in the country, new districts and municipalities have been created, and a new arrangement has been made by also referring to the municipality law, according to which existence of some of the municipalities were terminated based on the population criteria. The municipalities of Eminönü and Fatih Districts as well as their respective municipalities will be combined and become a single entity following the said arrangement. The risks, especially in the context of the tourism function of the region, which these Municipalities will come across by the end of this process will be discussed and presented in this paper.
\end{abstract}

Keywords: Historical Peninsula, tourism and local government, Fatih and Eminönü. 


\section{Introduction}

With a population of almost 12 million, Istanbul is a very important metropolitan located at the intersection of two continents. Having perhaps the most important privilege in terms of strategic location, Middle Eastern and European connections as well as cultural heritage, Istanbul has a multicultural identity despite some vanishing values. This city offers many identities and cultures to the service of today's people with a vast versatility. This is not only valid nationally but also internationally. The abovementioned multicultural structure, which can be one of the most important of all the "identity codes" of Istanbul, embraces us in different locations of the city. This structure vastly expresses itself in the Historical Peninsula that accommodates the "ancient city core" of the city. With the functions as well as historical and cultural values mentioned in the relevant literature, the Historical Peninsula is also an important center for global tourism.

"Historical Peninsula" is not only one of the ancient settlement areas of Istanbul but is also included in the UNESCO cultural heritage list with tangible and intangible values that are the fruits of intercultural civilizations and values that have been embraced by the city, and the Historical Peninsula is the symbol and tourism center of Istanbul. Also acting as the brand of the city, the Historical Peninsula accommodated two municipalities until today. These are Eminönü and Fatih Municipalities. However, a new legislation introduced in April 2008 has merged some municipalities. In this context, Eminönü and Fatih Municipalities have been merged to form a single municipality. This document will strive to evaluate the reasons and results of this implementation.

\section{Importance of Eminönü and Fatih Municipalities in the memory of Historical Peninsula}

In 1928, the Historical Peninsula that contained the central district of Istanbul was divided into two district municipalities: Fatih and Eminönü. Having been located right at the heart of metropolitan Istanbul where Asia and Europe meet, the Historical Peninsula is the focal point of transportation routes. The peninsula serves as a center for motorway, marine and railway systems.

This settlement, which ruled almost half of the Old World for almost fourteen centuries, is itself a monument of culture. In this context, having different subregional characteristics, Eminönü and Fatih municipalities host many important and original cultural assets that form the identity of Istanbul. This region is has had particular problems in the recent years in terms of losing its values and is facing a serious lack of planning, management and coordination; and is exposed to a significant risk of losing the cultural heritage and is being threatened by UNESCO.

The district of Eminönü is the second smallest district in Istanbul in terms of area, it is located completely in the historical core of the city and has important ports of the world inside the city walls and forms the most dynamic region of the city. Eminönü district is named after the Ottoman Marine Customs and Customs 
Authority that was located here and formed the central district of Istanbul together with Fatih district in the early years of the Republic. The population increased until 1955, when Eminönü district started to lose its population because many important neighborhoods of the district were turned into trade centers over time. The 1990 population was 83.444 and the most recent census showed 55.548 people. It occupies an area of $5 \mathrm{~km}^{2}$ with 33 neighborhoods.

The "Historical Peninsula" mostly hosts traditional trade centers and commercial functions rather than residential areas particularly in Eminönü district. Furthermore, the second intrinsic characteristic of the district is the administrative functions combined with the symbiotic functions and those that managed to preserve traditional locations despite the decentralization process after the 1980s, which resulted in movement across the city walls from the trade structure of the "Historical Peninsula". When the original informal trade and entertainment industry that formed as a result of tourism are combined with the abovementioned functions, the general lines of the commerce in the "Historical Peninsula" are determined. The Eminönü region hosts many universal and historical assets such as the Grand Bazaar, District of Inns, Beyazit, Cankurtaran, Blue Mosque Square, Hagia Sophia, and Topkap1 Palace. Among them is the Süleymaniye region, which is one of the original representatives of its kind in terms of an authentic "Turkish Settlement" with the architectural and sociocultural structure that was preserved until the 1960s. In this context, it is one of the most important regions of Istanbul in terms of culture and tourism potentials.

Eminönü region had always been the heart of the city with regards to traditional trade and manufacturing of handicrafts. It is one of the important centers of Istanbul in terms of textile and leather products, furniture, food products, jewellery, mats and wooden goods, carpet retailing and wholesale industries. In addition to the abovementioned traditional trade centers (Grand Bazaar, Spice Bazaar), the district also hosts fish and bread boats, the District of Inns, Hagia Sophia, Blue Mosque, Basilica Cistern, Topkapi Palace, Suru Sultani, Hippodrome, Suleymaniye Complex and the hundred-year old campus of Istanbul University and being the Central Business Area it is not only required for tourists but also for the entire population of Istanbul with transportation capabilities and social activities. (CBD) The night population of Eminönü is 50,000 but this reaches $4,000,000$ during the day and leads to the requirement for producing, controlling and managing the services required for such dynamism and versatility. Places evacuated by the upper and middle class are now being turned into workplaces or rented to singles in the form of hostels. There is a significant difference between the night and day populations of Eminönü, and buildings are being occupied illegally by newly migrated poor families or left to ruin. The urban texture transformation in Eminönü has reached its highest levels ever. The city is losing its characteristics of being a settlement and living area. This negative urban transformation is an important sociologic problem and will become much more important in the near future. This also leads to important problems in terms of municipality services because Eminönü Municipality receives an allowance proportional to the resident population. However, the service is provided to a much higher population. In this context, Eminönü 
Municipality has a low income but high expense. Fatih region, on the other hand, preserved its residential area structure and has become one of the most important land transportation cores. This region is surrounded by the Golden Horn and land up to the city walls in the north and is known as a region that hosts minorities. As a result, Fatih district is known as having residential areas that feature Turkish neighborhoods, minority neighborhoods and Gipsy neighborhoods that form one of the main building blocks of the city called "diversification".

The population of Turkey increased from 20.947 .188 in the 1950s to 67.803.927 today whilst the population of Istanbul increased from 1.166.477 to 10.018.735. According to census results obtained from the State Statistics Institute, the population of Istanbul was equal to $14.77 \%$ of Turkey in 2000 . This shows that Istanbul is the biggest city in Turkey in terms of the largest population. The 1950 population of Fatih district was 226.853 and reached 403.508 in 2000 . Despite the increase in population since 1950, its share in Istanbul decreased. This shows that there is a significant difference between the Istanbul Metropolitan Areas. Fatih district experienced a population increase until 1975. Afterwards, however, the population has tended to decrease in the district. The 1975 population of Fatih was 504.127 in 1975 and this has decreased to 403.508 .

\section{Dangers, threats and risks awaiting the Historical Peninsula today...}

Being one of the most important tourism destinations of Istanbul, the Historical Peninsula is intensely visited by every tourist that comes to Istanbul. As mentioned before, being a highly attractive region with landscape and Istanbul views, the Historical Peninsula is a highly determinant location in terms of tourism data for Istanbul.

Istanbul is the $20^{\text {th }}$ city among the ones that make the most revenue from tourism [2]. Today, almost $98 \%$ of the 6 million tourists that come to Istanbul visit the Historical Peninsula, which accommodates a high number of tourism facilities, bed quantity, entertainment facilities such as restaurants and bars among all the other districts of Istanbul. Furthermore, when it is taken into account that Istanbul will become the European Cultural Capital in 2010 and the 2015 target of 10 million tourists, the role that the Historical Peninsula will play is obvious. However, in addition to all these potentials and dynamics, the Historical Peninsula is about to face significant risks as a result of the vanishing population and aging structure since 1985 .

This data can be summarized as follows;

Eminönü district has lost almost $40 \%$ of its resident population

Fatih district has lost $18 \%$ of its resident population.

Eminönü district has lost mainly the female population, Fatih district featured no variation in the female-male balance.

Eminönü is rapidly losing the number of resident families and aging is closer to becoming a problem day by day. 


\section{Changing district borders and the Historical Peninsula after the new legislation...}

With an arrangement performed in 1928, the Historical Peninsula, in which the central district of Istanbul is located, has been divided into two separate district municipalities, Fatih and Eminonu. This divisional arrangement continued in a like manner for 80 years until 2008.

The Law 5747 on Establishment of Districts within the Metropolitan Municipality Border and Making Amendments to Certain Laws dated 22.03.2008 stipulates that counties a population of less than 2000 population will be transformed into villages, first degree municipalities under the Metropolitan Municipality will be annulled and new districts will be established. In addition to the foregoing, article 2.2 of the said law has annulled Eminönü District and Eminönü Municipality under Istanbul Province and the Historical Peninsula has been put under the administration of Fatih Municipality.

The grounds of the said application was the low daily population and to bring the Historical Peninsula under the administration of a single center. However, it should be remembered that Eminönü has a low resident population and an extremely high day population. The main issue here is that the budgets of local administrations are distributed proportionally to their resident populations and that the fact Eminönü experiences problems as a result of a high amount of expenses.

On one hand, the rapid decrease in the population and on the other hand, the aging process and demolition of physical and social structure as well as the unrecoverable falling process lead to serious problems. Despite the realization of a good analytic study so far, it has been too late to make a plan for the Historical Peninsula due to lack of coordination between authorities, over distribution of authorities and the extension of relevant problems that have led to underdevelopment of the region and features an internationally important risk of losing the values that the region owns. As frequently mentioned by UNESCO, the importance of the problem is evident with the threat of removal from the World Cultural Heritage List.

It is obvious that no correct, permanent and planned steps have been taken in this area, which also experienced lack of proper administration until today. In this perspective, the process of merger seems to be the right solution but it should be discussed in depth for all aspects of the Historical Peninsula, which has an intercultural value.

Administration of the Historical Peninsula by one single hand is not a new approach. Various projects have been pronounced from time to time about this issue starting from the end of 1990s. However, the point, which should not be neglected here, is that administration of the Historical Peninsula by one hand, though it is the correct approach, may not mean the existence of one municipality, because merger of the districts will lead to new problems in terms of the municipalities, which are already having great problems regarding resources and activities. Even in their current condition, both Eminonu and Fatih municipalities doubtlessly experience certain problems in terms of efficient and 
effective utilization of scarce resources, urban protection, efficient urban administration, etc. Whereas the municipalities receive a share parallel to their populations, a resource for 55 thousand people, which is the population of Eminonu, is transferred to Fatih municipality as a result of the new regulation, the burden to be undertaken by Fatih municipality has increased considerably. It should be considered once more with the new regulation how the municipality resources will be organized in terms of protection.

Furthermore, the basic target of the Development Plan Aimed At Protecting the Historical Peninsula, the execution of which has been currently stayed, is to increase the resident population and the recruitment areas connected with them, it seems that removing Eminonu district from the status of district due to the decrease in population is a conflicting decision. It is apparent that the said area could not be adequately managed and no correct, permanent and planned steps are taken in this area. From this perspective, this process, which assumes the merger to be a correct step, should be analyzed from all dimensions, and the issue should also be discussed with specific reference to the Historical Peninsula, which has acquired a trans-cultural level.

\section{How should a model be designed in the presence of the risks facing the Historical Peninsula?}

This area, which is perhaps the most important tourism destination point of Istanbul Metropolitan Area, is accepted and administered as an open air museum. In this regard, this area, which is spread over 17 ha in total as the area of two municipalities merged following the new regulation, and which hosts 102 neighborhood governing units within its body, has a quite specific profile in terms of demographic movements and data. Whereas the settled population reaches 500 thousand in total, the day population reaches 4 million, and consequently it reaches a size and dynamic that challenges the scale economies, which is hard to perceive and manage.

It is of no doubt that there is an obvious benefit for ensuring coordination and organization, taking common decisions in terms of realizing control and cooperation and executing some services from one single hand, however, it is not profitable to destroy the current system and to abolish the district organizations (Eminonu District and Fatih District), which are the extensions of the central administration, and the municipalities (Eminonu and Fatih Municipalities), which are the local administration units and to unite them under a single administration.

The local administrations' budget, which is prepared annually, is given according to the population residing in the region during the night, as indicated before, and the day population is not taken into consideration. Thus, the new formation, which does not bring any regulation on this issue, fails to produce a response to this problem, leaving the local administrations more helpless in the presence of the problems of an increasing and merging area. This constitutes a significant problem for both municipalities, which experience budget deficit and debts. 
Another important subject is related to the problems experienced by the whole Historical Peninsula in the planning system and process. It is not possible to say that the Historical Peninsula could be a part of an efficient and holistic planning system. As a result of the lawsuits opened against the Istanbul Master Development Plan Aimed At Protecting the Historical Peninsula, which was approved on 02.11 .1990 , with a scale of $1 / 5000$, the plan in question was cancelled on 17.11.1994 with the justification that the "plan lacks the function of protecting the Historical Peninsula", that, on the contrary, "it could lead to the destruction of the archeological, historical and cultural assets of the Historical Peninsula with the transportation and density resolutions taken", and, while the appeal processes were pending, the whole Historical Peninsula, which covers Eminonu - Fatih districts, was announced as a Protected Area with the decision of the Board of Protecting Cultural and Natural Assets dated 12.07.1995 No. 6848 .

It has become necessary to prepare a new plan pursuant to the law in place of these plans, which have become impossible to implement due to the area being announced as a Protected Area. While the planning works, which were commenced within the body of the Metropolitan Municipality, should have been completed within 1 year as per the Law on Protecting Cultural and Natural Assets No. 2863, amended by Law No. 3386, these were not completed within due time, and thus, the constructions continued within the frame of temporary settlement, and the Historical Peninsula was subject to unplanned structures. In addition, applications were performed on a plot basis without taking into consideration the environmental factors and functions, let alone a holistic planning understanding under the conditions of temporary restructuring. This means a partial, non-systematic and coincidental development of the area.

Main indicators of the problems of the Historical Peninsula include such issues as:

- Impacts of the motion for stay ruled for the Development Plan Aimed At Protecting the Historical Peninsula and Environmental Arrangement Plan scaled 1/100 000 on the Historical Peninsula,

- The problem of the harmonization of in particular the renewal projects, which are commenced together with new legal processes throughout Istanbul, with higher scaled plans, and the reflections to the Historical Peninsula

- Impacts of the projects, which are designed for different regions of Istanbul, on the Historical Peninsula (great transportation projects, rail systems, tunnels, port decisions such as galaport vbg kruvazier)

- Commencement of the area management process in the Historical Peninsula

- The role of and the identity to be undertaken by the Historical Peninsula in the process of Istanbul 2010 European Culture Capital.

The first point to be highlighted in the presence of this picture should be to immediately generate new strategies and actions plans and to put them into practice rapidly with a holistic viewpoint in order to launch a well planned process before a restructuring and changing the existing borders. 
It is apparent that failure to complete the planning process is the most significant threat before the Historical Peninsula. The fact that the local administrations do not have the required vision other than their authorities, and a sufficient budget in line with this, constitutes another thread that chokes the process. Whereas the planning has been under the authority of Istanbul Metropolitan Area administration, which is a superior unit, to date, and considering the issue from this aspect, this constitutes no obstacle in terms of interpreting the are as a whole, the fact that no sufficient precautions were taken and no initiatives were developed in terms of both planning and urban and tourism administration processes, is not a lack of fortune, but an unacceptable lack of any vision. For this reason, instead of simple administrative border changes, comprehensive and sustainable steps and emergency action strategies are preconditions for the protection, sustainability and the administration of this area, which is both a national and transnational heritage region.

In this regard;

- The Historical Peninsula should first be assessed in terms of its current dynamics and demographic assets.

- Relevant budgeting processes should be generated within a flexible restructuring scheme which is realistic and which covers the whole system. The region, which has received around one third of the budget it required up to now, should have access to real values in this context.

- The "area management" process should be analyzed with a design that covers the whole historical peninsula. However, "clumsy" organizations in restructuring should be avoided

- All details from higher scaled protection-utilization balances, renewal works, restoration, renovation and restitution actions to urban design scales, urban furniture and urban information systems, should be considered, designed and applied as a whole.

- In the Istanbul Metropolitan Area, where the management and participation processes are processed with difficulty and under distortion, new but healthy, objectives and applicable participation models should be designed for this area, and specific models for the regions should be discussed that have very different user profiles.

- Such processes as advertising and presentation should be planned for the works to be launched in the area, and it should be ensured that this area, which has gone out of date and which looses blood, becomes bright again, and it should be encouraged and put into the agenda accordingly.

- In this process, the speculation problem, which Istanbul experienced particularly in the scope of major projects, is a very big risk for the Historical Peninsula. It is a requirement that a very controlled process should be undertaken in this area, which will apparently be the focus point of the intense interests of all relevant sectors from small capital groups to major real estate sector representatives, foreign investors, land speculators, and that the specific legal processes and institutions should be restructured and operated in this context, that the current rights and 
properties should be protected and a speculative action towards third parties should be prevented.

- Abstracting the Historical Peninsula, which is the leading figure among the tourism dynamics of the Istanbul Metropolitan Area, from the general of Istanbul and taking it in isolation will be a mistake. This area, which should be analyzed as a whole from the Galata region, which is located on its opposite coast, to the other side of the Golden Horn, from Beyoglu, Pera region to the new cultural centers of the city, must be worked with a planning and planning management system.

\section{Conclusion}

With authentic examples of tangible and intangible cultural heritages under supranational dynamics and potentials, the Historical Peninsula is not experiencing a successful period in terms of planning and management. The most important bottlenecks in front of the Historical Peninsula, which hosts a total of 5796 registered structures (monumental works, official buildings, industrial facilities, civil architecture samples) and 1069 lost monumental works, and which has a very specific profile with "urban archeological protected sites" it hosts within its borders, involve earthquakes, large fires and particularly the lack of plans and erroneous planning decisions (increasing the development rights, transportation decisions that are isolated from the whole, planning approaches where the concept of protection is ignored, the fact that the current inventory could not be clarified until very recently), the conflict of authority in planning, and the lack of consciousness in people. In addition to planning and management problems, there are also planning organization and coordination problems in the area. Having been managed without a plan, the region has also experienced a lack of sufficient and proper "site management" due to lack of upscaling and urban design plans. These problems can affect not only the tourism data of the Historical Peninsula but also that of Istanbul as a whole, and horizontal border organizations and arrangements as a result of political concerns about administrative borders will not correct the problems and would even give rise to them.

As a final word; it is an unacceptable mischance to try to administer the Historical Peninsula without any plan and principle. There is a very severe danger not only from the tourism point of view but also in terms of the loss of international cultural heritage, and the most reasonable solution in the presence of this problem is to encourage integral urban development, providing the condition of sustainability principles, and justifying the urban renewal and protection works immediately with scientific realities.

\section{References}

[1] UNESCO The World Heritage List Reports, 2004.

[2] Tourism and Entertainment Industry Global Performance Evaluation report 2007, Turkey 
[3] Historical Peninsula Report: Diversity of Historical Peninsula - İstanbul, Y1ldı Technical Universit, Department of Urban and Regional Planning, İstanbul, 1999, İstanbul

[4] Eminönü Municipality Tourism Statistics, 2008. 